\title{
Dublin Tech Summit - a Review
}

\author{
Dr. Brid Lane \\ School of Business and Law \\ Dublin Business School \\ Dublin, Ireland
}

(C) Brid Lane. This work is licensed under the Creative Commons Attribution-

NonCommercial-ShareAlike 4.0 International License. To view a copy of this license, visit https://creativecommons.org/licenses/by-nc-sa/4.0/ .

Dublin has long built itself a reputation as being a tech hub, with many of the large IT players (Google, Microsoft, Facebook, etc.) having their European headquarters here. The annual Web Summit (https://websummit.com) had its origins in Dublin in 2009 and for several years flooded the capital with investors, tech-heads, start-ups, SMEs and MNEs and anyone with a techie bent, from around the world. In 2016 it moved to Lisbon and its absence left a notable gap in the Dublin tech scene. In 2017, we more than filed this gap with the Dublin Tech Summit (http://dublintechsummit.com).

Held over 15th and 16th February at the Dublin Conference Centre, it managed to be even more varied in many ways than the web summit, and this was most obvious in the number of women attendees. For most tech conferences, the stereotype varies between polo-necked males in black jeans (the tech-heads) and the be-suited gent (the business types), and any other personas are under-represented. The Tech Summit had almost $49 \%$ female attendance.

This was down to the work and foresight of the CEO Noelle O'Reilly (@NoelleNate), and helped in no small part by groups such as http://witsireland.com/cms/ (Women in Technology and Science). The sheer variety of speakers (over 200) across 8 stages meant there was something for every one of the 10,000 attendees, and stereotypes went out the proverbial window. Of course, with that many people, technology is needed to handle the introductions - all visitors were greeted by RoboThespian.

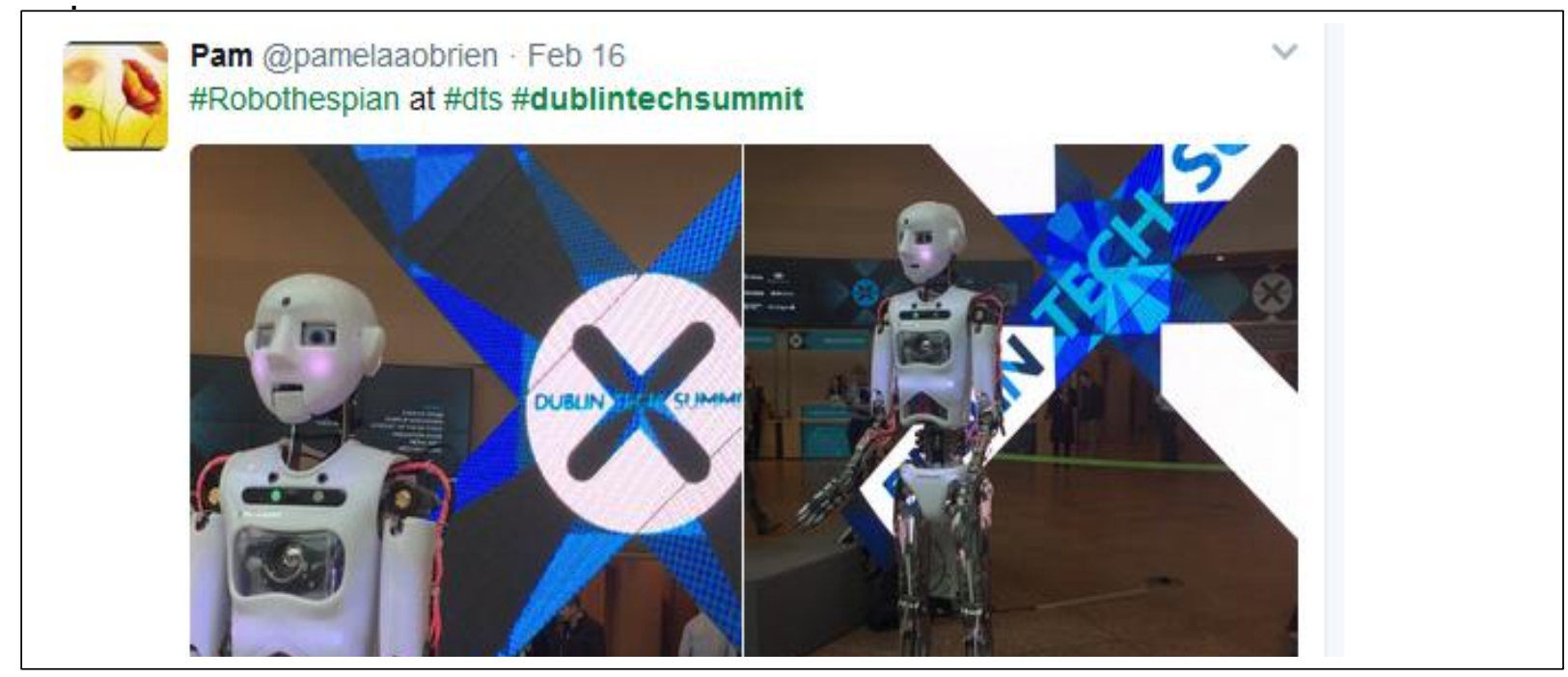


The Fashion-Stage seemed to be as popular with the men as with the women attendees. "Fashtec" or "wearables" is fast moving towards making our clothes smarter, so we become walking/talking exponents of the Internet-of-Things. We can even 3D-print the fabric involved - this has notable implications for the textile industry - whether good or bad, remains to be seen.

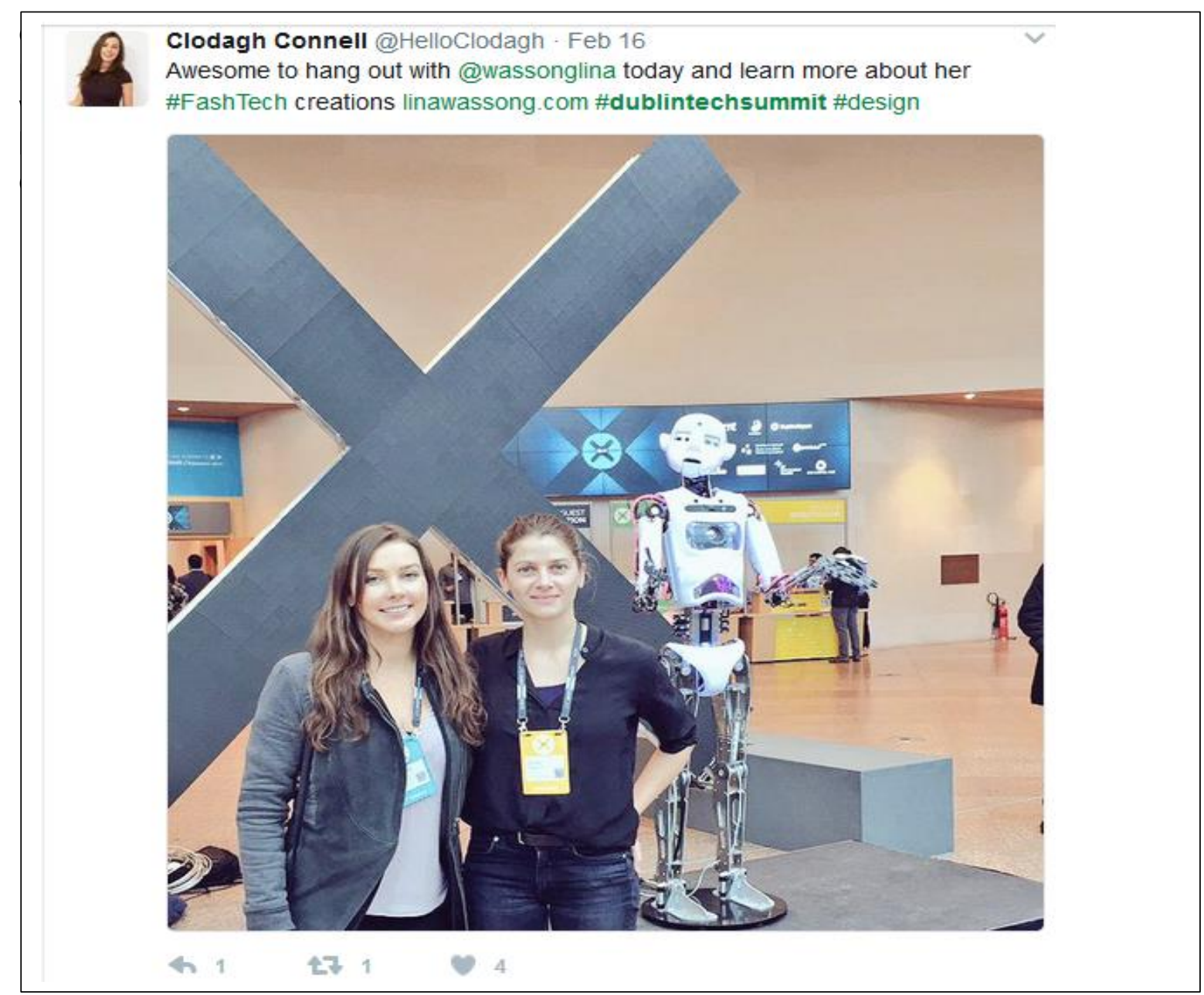

The 'wearables' also featured in the Healthcare-Stage. We do not need reminding that the current system of healthcare is unsustainable. It is a relief then to hear about innovations such as patients sent home with cloud-based, always-on, discreet, monitoring devices that alert the right people at the right time if there's a need. Wearables such as the Fitbit (and other branded alternatives) can alert the wearer to impending problems. Remote medical diagnostics are not totally new but have the potential for mainstream deployment. We might see an end to the dreaded hospital trollies yet. 
Technology has been invading the world of finance for many years. Bitcoin and other 'alternative' currencies have had their peaks and troughs in recent years. However, Blockchain is what has the Fintech people particularly excited. It has uses and applications well beyond the financial world of ledgers of bitcoin transactions of the dark web. It genuinely has the potential to revolutionise transactions through transparency and traceability for all parties across a range of transaction types. It spurred the 'twitterati' into action:

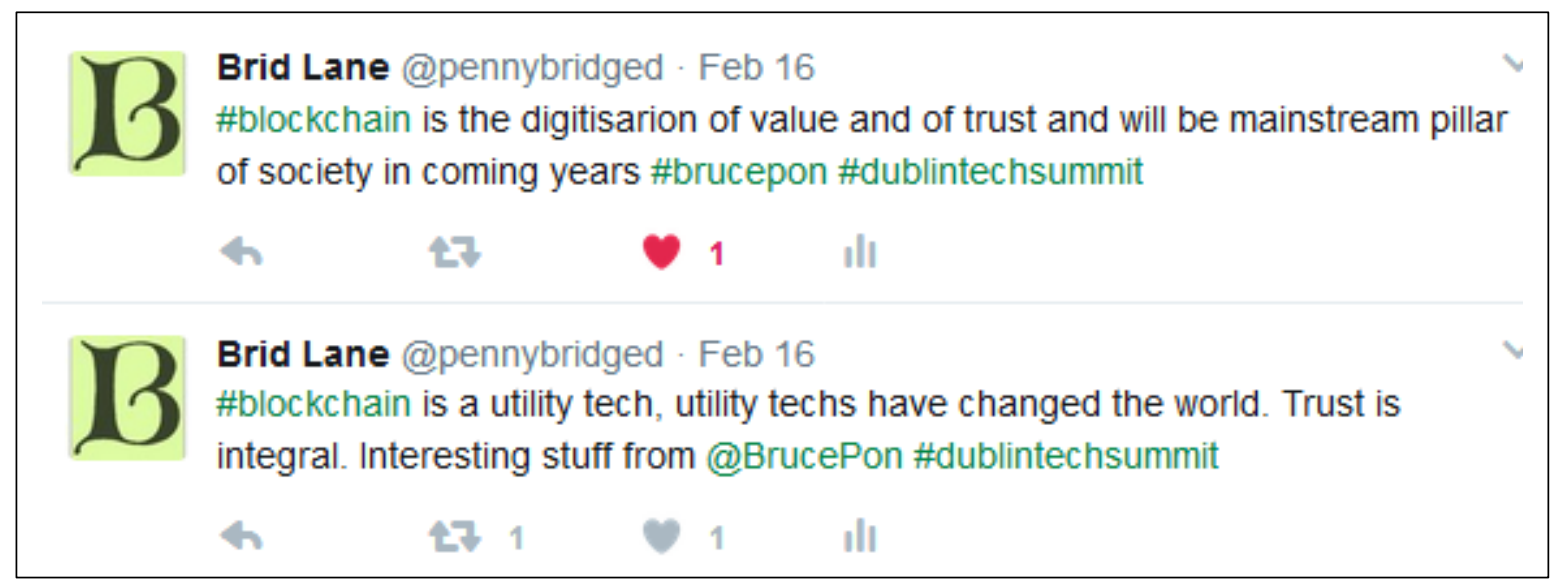

Fintech is back on the agenda for next year's conference (April 2018), along with a host of other stages. Cloud computing is a decade old this year and has more than found its place in the IT world. It is a facilitator of some of the other themes heading our way next year - Internet-of-Things and big data in particular. Let us hope that women will continue to be as well represented next year as they were this year. Conferences such as these are an opportunity for attendees to learn about what is happening in the tech world, make contact with like-minded people, share ideas, and encourage dialogue and exploration of the technologies of the day. By encouraging women to become more and more involved, the world of tech is headed on the right track to gender equality - and it is about time too. Final word goes to keynote speaker Cindy Gallop:

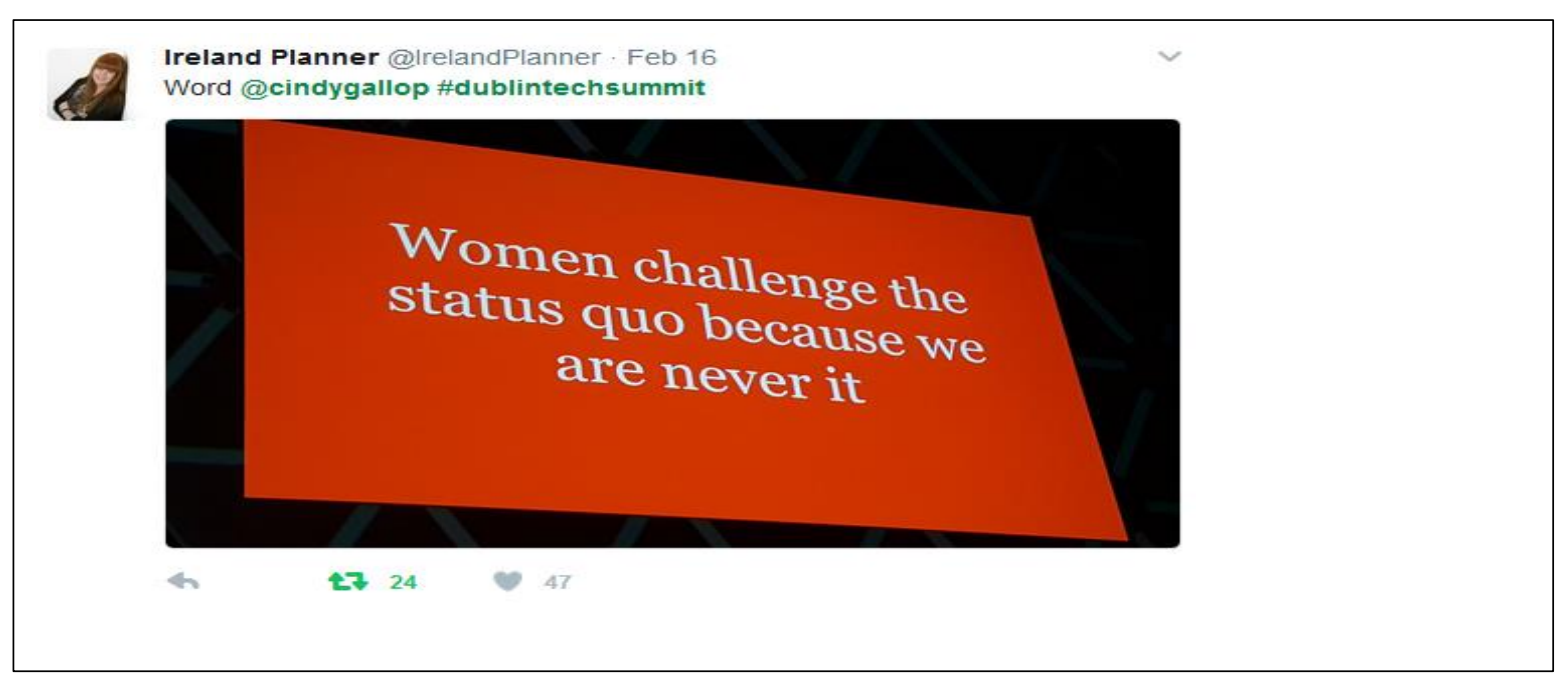

